\title{
Effects of Motor Tasks through Photos and Videos in Patients After Stroke
}

\author{
Efeitos da Demonstração de Tarefas Motoras por Fotos e Vídeos \\ em Pacientes Pós-Acidente Vascular Encefálico
}

\author{
Fabíola Rodrigues de França Campos ${ }^{a}$, Antônio Pereira Júnior ${ }^{b} \&$ Tania Fernandes Campos ${ }^{*}, b$ \\ ${ }^{a}$ Universidade Estácio de Sá, Rio de Janeiro, RJ, Brasil \\ $\&{ }^{b}$ Universidade Federal do Rio Grande do Norte, Natal, RN, Brasil
}

\begin{abstract}
The aim of the present study was to examine the effects of motor tasks through photos and videos in post-stroke patients. Participants were 12 patients and 10 control people. Five functional tasks were presented in four different sequences and participants had to indicate the ones which reached the goal correctly. By ANOVA it was found that the response time of the patients was greater than of the control group (photos $=$ patients: $4833 \pm 310 \mathrm{~ms}$, control: $1112 \pm 76 \mathrm{~ms}, p=.0001$ and videos $=$ patients: $3655 \pm 242 \mathrm{~ms}$, control: $2451 \pm 270 \mathrm{~ms}, p=.0001$ ). Patients performed better with videos $(p=.001)$. These results may influence therapeutic strategies and enable a discussion about a possible impairment of the mirror neuron system.

Keywords: Stroke, recognition, motor activities, activities of daily living, observational learning.

Resumo

O objetivo deste estudo foi analisar os efeitos da demonstração de tarefas motoras através de fotos e vídeos em pacientes pós-AVE (acidente vascular encefálico). Participaram 12 pacientes e 10 controles. Cinco tarefas funcionais foram apresentadas em quatro sequências diferentes e os participantes indicavam aquela que alcançava o objetivo corretamente. Pela ANOVA verificou-se que o tempo de resposta dos pacientes foi maior (fotos = pacientes: $4833 \pm 310 \mathrm{~ms}$, controle: $1112 \pm 76 \mathrm{~ms}, p$ $=0,0001$ e vídeos $=$ pacientes: $3655 \pm 242 \mathrm{~ms}$; controle: $2451 \pm 270 \mathrm{~ms}, p=0,0001)$. Os pacientes apresentaram melhor desempenho com os vídeos $(p=0,001)$. Estes resultados podem influenciar as estratégias terapêuticas e permitir uma discussão a respeito de um possível impedimento do sistema de neurônios-espelho.

Palavras-chave: Acidente vascular encefálico, reconhecimento, atividades motoras, atividades da vida diária, aprendizagem observacional.
\end{abstract}

The motor rehabilitation of stroke patients is a long and tedious process that can rely on several therapeutic approaches currently available. The traditional correction/ facilitation method, for instance, uses therapeutic exercises and neuromuscular facilitation techniques to decrease sensory-motor deficits and promote motor improvement (Knott \& Kabat, 1954). A more recent approach, however, focuses on motor learning due to the practice or training of specific sequence of movements in functionally relevant contexts (Krakauer, 2006).

\footnotetext{
* Mailing address: Departamento de Fisioterapia, Universidade Federal do Rio Grande do Norte, Av. Senador Salgado Filho, 3000, Natal, RN, Brazil 59066-800. Email: taniacampos@ufrnet.br, fabiolafcampos@gmail. com and apereira@ufrnet.br

Acknowledgements: This research was supported by Support Program Graduate/Coordination of Improvement of Higher Education Personnel (PROAP/Capes) and National Council for Scientific and Technological Development (CNPq).
}

The discovery of mirror neurons in the prefrontal cortex of monkeys (Gallese, Fadiga, Fogassi, \& Rizzolatti, 1996) and humans (Mukamel, Ekstrom, Kaplan, Iacoboni, \& Fried, 2010) based on non invasive neuroelectrophysiological assessment or functional brain imaging techniques showed that motor representations in the brain could be activated when individuals learn motor actions via execution (as in traditional motor learning), imitation, observation (as in observational learning) and motor imagery (Buccino, Binkofski, \& Riggio, 2004; Page, Szaflarski, Eliassen, Pan, \& Cramer, 2009; Stefan, Cohen, \& Duque, 2005). It is therefore believed that this multi-sensory action-observation system enables individuals to (re) learn impaired motor functions through the activation of these internal action-related representations (Sale \& Franceschini, 2012). This finding suggested that the implicit activation of motor programs could be used for neuropsychological rehabilitation of stroke patients (Iacoboni \& Mazziotta, 2007). 
For instance, it had already been shown that motor learning is markedly improved when verbal instructions given to individuals are replaced by videotapes, films, or photographs depicting the correct movement sequence that needs to be trained (Schmidt, 1991). A recent study with healthy subjects showed that learning by observation of videos, and the neural substrate of the observationexecution matching system, is organized to represent the goal of the learned motor task, rather than the specific effector used during learning itself (Williams \& Gribble, 2012).

A modality of physical therapy based on observation has been successfully tested for stroke rehabilitation (Celnik, Webster, Glasser, \& Cohen, 2008; Ertelt et al., 2007) and has been called videotherapy indicating that the observation in combination with physical training may increase the effects of motor training after stroke and emphasizes the importance of action perception in neurorehabilitation (Ertelt, Hemmelmann, Dettmers, Ziegler, \& Binkofski, 2012). The subsequent repetitive execution of the observed actions reinforces the cortical representation of action. The mirror neuron system provides a clearly defined neurophysiologic background for this new approach. Various studies were carry out regarding the clinical use of action observation for motor rehabilitation of sub-acute and chronic stroke patients, furthermore, because activation of action representations by observation takes place also without the performance of active movements, the videotherapy is also potentially suitable for patients with acute strokes (Ertelt et al., 2012).

However, as far as we know, there is no study comparing the performance of stroke patients on the recognition of motor sequences displayed with either photographs or videos. In order to answer the question whether there is any difference in patient's performance when trying to mentally imitate movements displayed either as static (photos) or dynamic (videos) sequences, we used representations of activities of daily life (ADLs) and asked the patients which displayed the correct sequence of movements and which had more chance of reaching the implicit goal. Thus, the aim of this study was to examine the effects of the demonstration motor tasks through photos and videos in patients after stroke. We found the need to analyze what type of demonstration could improve the capability of action observation of patients in order to provide a basis for rehabilitation and to allow a discussion about a possible impediment of the mirror neuron system.

\section{Material and Method}

\section{Subjects}

The sample consisted of 12 stroke patients recruited from the physical therapy unit of a Public Hospital and 10 controls. We adopted the following inclusion criteria: age between 45 and 75 years, both gender, literate, first clinically evident stroke (controlled via medical history, patient's data in the respective clinic), unilateral cerebral lesion and primarily motor symptoms (controlled by standard neurological examination), chronic stage of stroke (after 6 months), absence of serious cognitive disorders (controlled by medical evaluation), and non-use of sedatives, antidepressants, or neuroleptics. The inclusion criteria for the control group were: age between 45 and 75 years, both gender, literate, absence of pathology, and non-use of regular medication.

\section{Procedures}

The study was approved by the local Research Ethics Committee. All the participants were informed about the details of the procedures and signed a written informed consent. We kept a record of the patient's medical history, including lesion location, diagnosis, and duration of sequelae.

We used the NIHSS (National Institute of Health Stroke Scale) to determine the degree of neurological impairment of the patients. Awareness level, eye movements, visual field, facial movements, motor function, and upper and lower limb ataxia were assessed, in addition to sensitivity, language, and the presence of dysarthria and spatial negligence (Caneda, Fernandes, Almeida, \& Mugnol, 2006). To assess the overall health of control individuals we used the CIRS (Cumulative Illness Rating Scale; Parmelee, Thuras, Katz, \& Lawton, 1995), which provides data on the status of six systems: cardiovascular/respiratory, gastrointestinal, genitourinary, musculoskeletal, integumentary, neuropsychological, and endocrine, with a severity scale of 0 to 4 points.

The patients and the controls were selected by simple randomization, according to the arrival at the physiotherapy service and eligibility criteria for inclusion either one of two demonstrations: with photos and using videos (Figure 1).

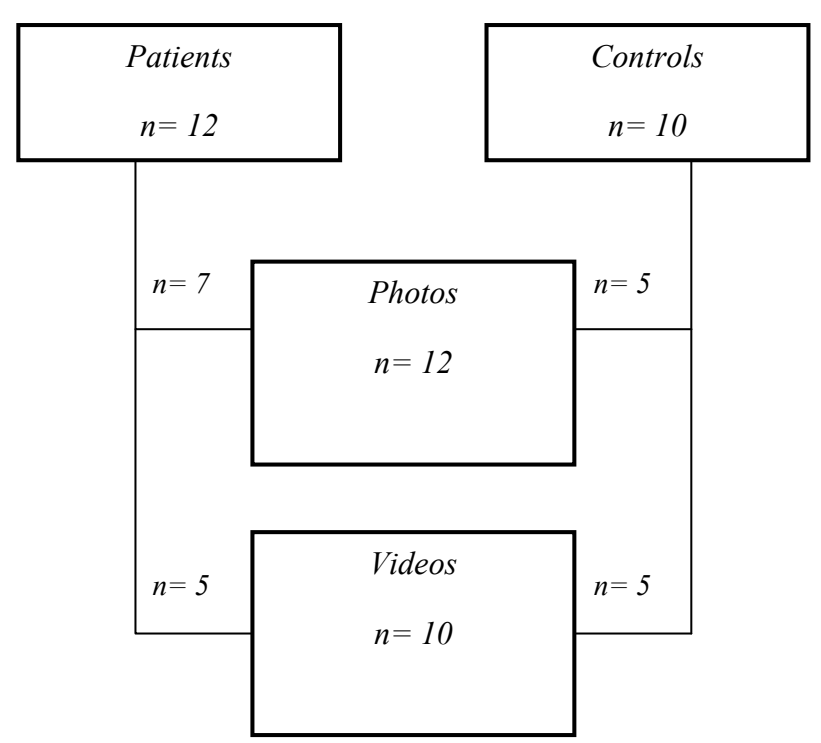

Figure 1. Schematic diagram of the study sample. 
Five types of ADLs (drinking juice, combing hair, feeding, brushing teeth, and answering the telephone) were shown to each participant. Each activity was presented in 4 sequences, as shown in Figure 2, for 4 seconds. The sequences were presented individually on a computer screen, using either photos or videos. After, the 4 sequences were shown simultaneously on the screen and the subject indicated which one displayed the correct sequence of movements and which one had more probability of reaching a goal. The screen was then turned off and the subject was informed whether he/she had been successful. The sequences previously randomized for each motor activity. In total, 24 trials were made for each activity; the subjects gave 120 responses for a total of 2640 data items.

\section{Sequence 1}
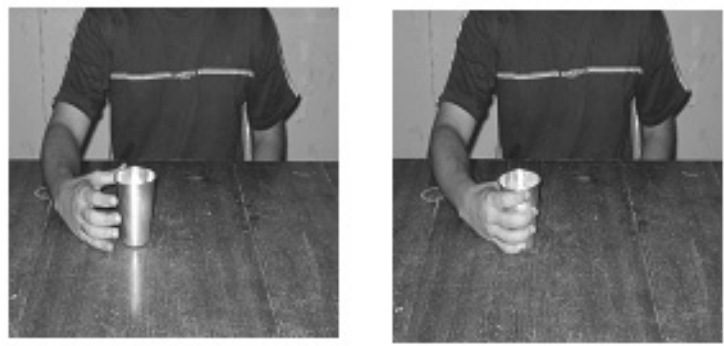

Sequence 2
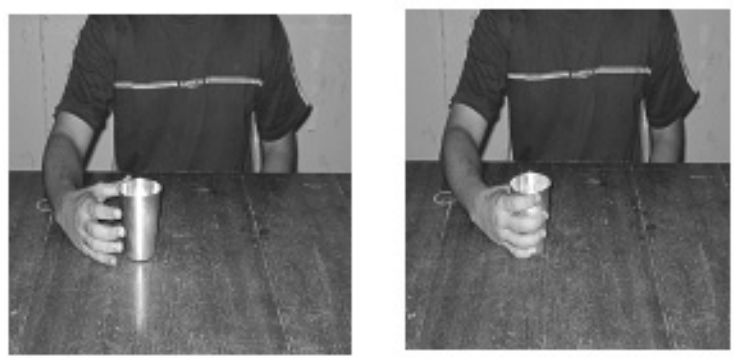

\section{Sequence 3}
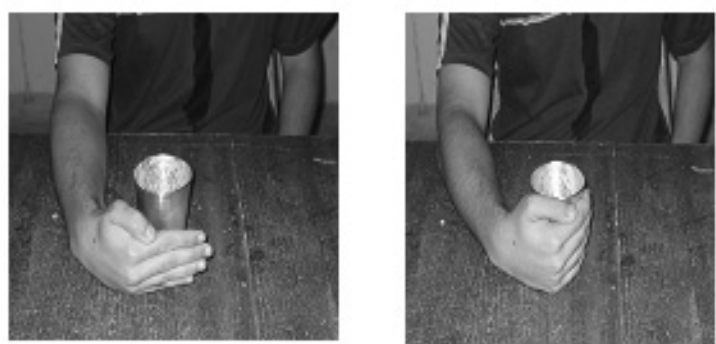

\section{Sequence 4}
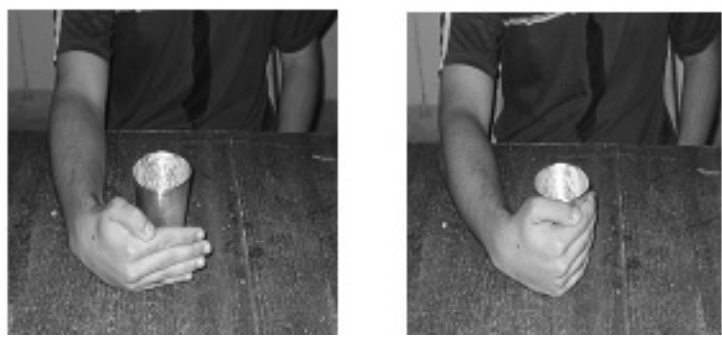
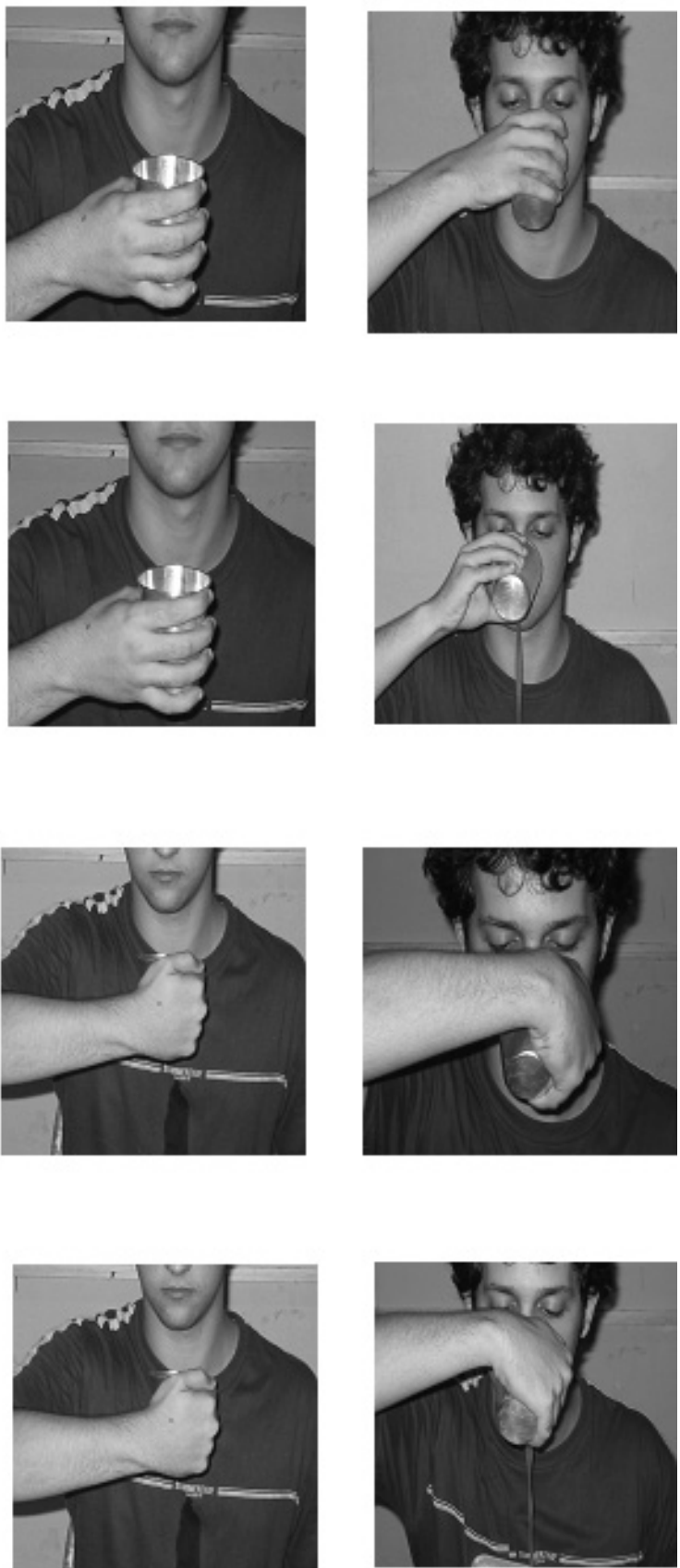

Figure 2. Motor-sequence recognition of drinking juice. In sequence 1, the movement is correct and the objective is reached, since the man managed to drink the juice. In sequence 2, the movement is correct and the object is not reached because the juice is spilled. In sequence 3, the movement is incorrect and the objective is reached. In sequence 4 , the movement is incorrect and the objective is not reached. 
Campos, F. R. F., Pereira Júnior, A. \& Campos, T. F. (2014). Effects of Motor Tasks through Photos and Videos in Patients After Stroke.

\section{Data Analysis}

After performing a normality test (Shapiro-Wilk) to the data, we used the unpaired Student $t$ test to compare the demographic and clinical characteristics of the sample. ANOVA (Tukey's post-hoc test) was applied to to compare response times in the motor-sequence demonstration with the factors mode (photos or videos) and trials. We used the chi-square test to compare the frequency of correct and incorrect responses and frequency by gender and cerebral hemisphere affected. For statistical analysis we used the SPSS 14.0 (Statistical Package for the Social Science) software and the significance level was set at $5 \%$.

\section{Results}

The demographic and clinical characteristics of the sample are shown in Table 1. By analysis found no significant difference in the patients and controls between photos and videos regarding gender, age, schooling, the cognitive status (measured by MMSE) and general health (measured by CIRS). In patients no significant difference was found regarding the affected hemisphere and neurological grade (measured by the NIHSS), but significant difference was found regarding the sequelae time, in which patients with demonstration videos were longer sequel (Table 1).

Table 1

The Demographic and Clinical Characteristics of Stroke Patients and Controls According to the Groups of Photos and Videos

\begin{tabular}{|c|c|c|c|c|c|c|c|}
\hline \multirow{2}{*}{ Variables } & & \multicolumn{3}{|c|}{ Patients } & \multicolumn{3}{|c|}{ Controls } \\
\hline & & Photos & Videos & $p$ & Photos & Videos & $p$ \\
\hline \multirow[t]{2}{*}{ Gender $(n / \%)$} & Women & $1 / 12$ & $1 / 20$ & .890 & $4 / 80$ & $2 / 40$ & .068 \\
\hline & Men & $6 / 88$ & $4 / 80$ & & $1 / 20$ & $3 / 60$ & \\
\hline $\begin{array}{l}\text { Age - years } \\
\text { (mean } \pm \text { standard deviation) }\end{array}$ & & $62 \pm 23$ & $62 \pm 26$ & .863 & $54 \pm 22$ & $54 \pm 23$ & .658 \\
\hline $\begin{array}{l}\text { Schooling }- \text { years } \\
\text { (mean } \pm \text { standard deviation) }\end{array}$ & & $7 \pm 3$ & $5 \pm 2$ & .186 & $11 \pm 4$ & $10 \pm 5$ & .064 \\
\hline $\begin{array}{l}\text { MEEM - scores } \\
(\text { mean } \pm \text { standard deviation) }\end{array}$ & & $24 \pm 3$ & $23 \pm 3$ & .715 & $28 \pm 1$ & $27 \pm 1$ & .057 \\
\hline $\begin{array}{l}\text { CIRS - scores } \\
\text { (mean } \pm \text { standard deviation) }\end{array}$ & & $2.5 \pm 1.3$ & $2.4 \pm 2.0$ & .844 & $1.6 \pm 1.0$ & $1.6 \pm 1.2$ & .870 \\
\hline \multirow[t]{2}{*}{ Affected hemisphere $(n / \%)$} & Right & $4 / 57$ & $2 / 40$ & .867 & - & - & - \\
\hline & Left & $3 / 43$ & $3 / 60$ & & - & - & - \\
\hline $\begin{array}{l}\text { Sequelae time - months } \\
\text { (mean } \pm \text { standard deviation) }\end{array}$ & & $11 \pm 7$ & $25 \pm 14$ & .023 & - & - & - \\
\hline $\begin{array}{l}\text { NIHSS - scores } \\
\text { (mean } \pm \text { standard deviation) }\end{array}$ & & $1.6 \pm 1.3$ & $4.2 \pm 3.2$ & .064 & - & - & - \\
\hline
\end{tabular}

In the patients group we found a significant difference in response times in the videos between the $1^{\text {st }}$ and $2^{\text {nd }}$ trials $(p<.0001)$, and the $3^{\text {rd }}$ and $4^{\text {th }}$ trials $(p<.0001)$. In the photos, there was a significant difference between the $1^{\text {st }}$ and $2^{\text {nd }}$ trials $(p<.0001 ;$ Figure $3 \mathrm{~A})$. In this group analysis showed a significant difference between the recognition of videos and photos only the first trial $(p=.025)$.
In the control group, the videos showed a significant difference in response times between the $1^{\text {st }}$ and $2^{\text {nd }}$ trials $(p<.0001)$ and the $4^{\text {th }}$ and $5^{\text {th }}$ trials $(p<.0001)$. In the photos, no significant difference was found among trials $(p<.005)$, suggesting the presence of a stabilizing effect at the beginning of the test (Figure 3B). In this group when comparing the recognition of videos and photos a significant difference was also found on the first trial $(p=.028)$. 
A

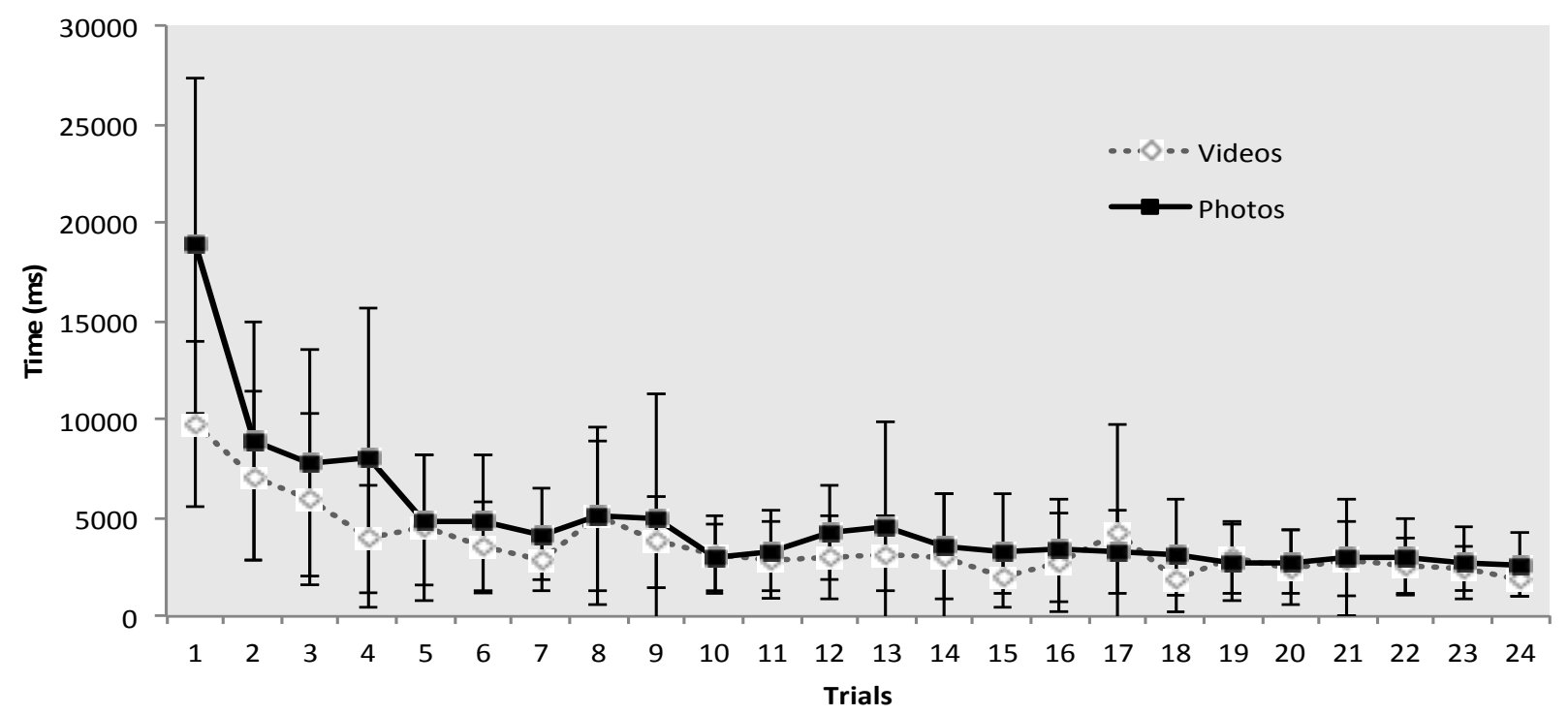

B

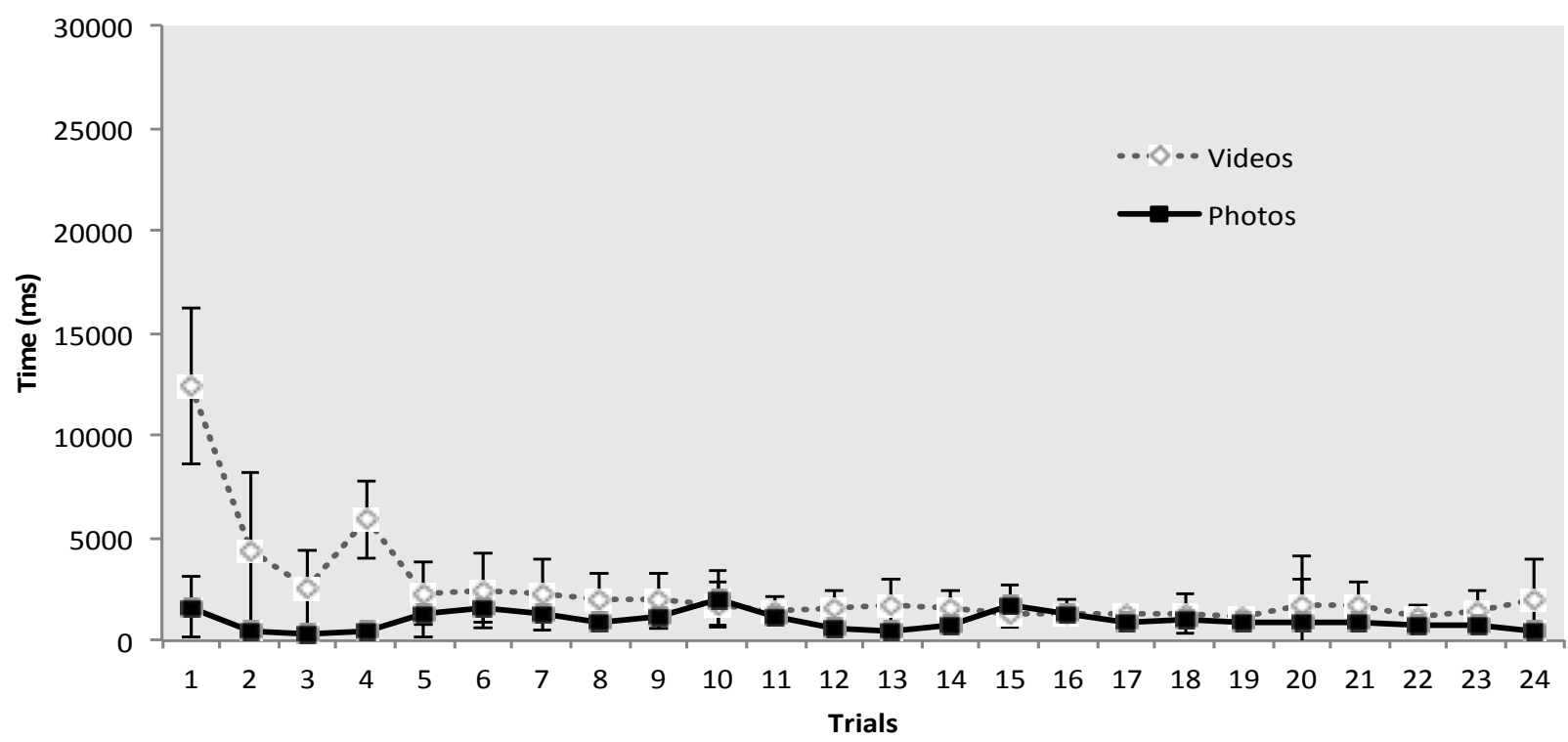

Figure 3. Mean and standard error recognition time of motor activities for the patients (A) and the controls (B), presented in photos and videos during 24 trials.

Considering the average response time of the 24 trials in the recognition test, a difference was found between patients and controls on the photos (patients: $4833 \pm 310$ ms; control: $1112 \pm 76 \mathrm{~ms} ; p=.0001)$ as well as on the videos (patients: $3655 \pm 242 \mathrm{~ms}$; control: $2451 \pm 270 \mathrm{~ms}$; $p=.0001$; Figure 4). In average, the patients had a longer response time in the photos sequences than in the videos $(p=.001)$, whereas the inverse pattern was found for the control individuals ( $p=.001$; Figure 4$)$.
Analysis of the frequency of choosing one of the 4 movement sequences showed a significant difference between patients and controls $(p=.0001)$. The patients chose the correct sequences (1 and 2) more frequently during videos $(98 \%)$ than during photos $(88 \%$; Table 2 ). The controls, on the other hand, did not display any significant difference when comparing response frequencies between the videos and photos $(p=.166$; Table 2). 


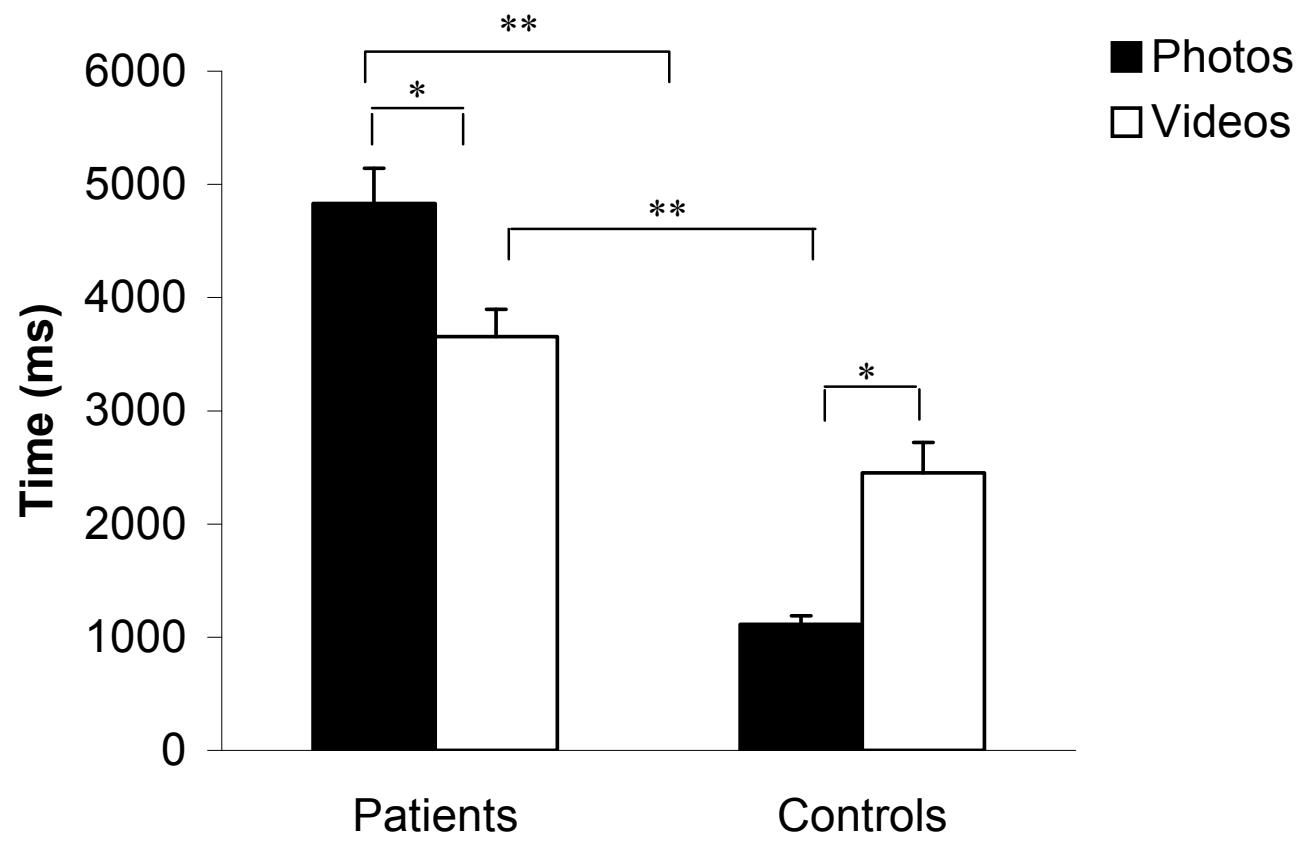

Figure 4. Mean and standard error of sequence recognition time of motor activities for the patients and the controls, presented in photos (separate parts) and videos (continuously).

Note. *Significant difference between photos and videos. ${ }^{* *}$ Significant difference between patients and controls.

Table 2

Absolute and Percentage Frequencies of Response Types in the Motor-Sequence Recognition Presented in Photos and Videos for the Group of Patients and Controls

\begin{tabular}{ccccccccc}
\hline & \multicolumn{4}{c}{ Photos } & \multicolumn{5}{c}{ Videos } \\
\cline { 2 - 8 } & $\mathrm{S} 1$ & $\mathrm{~S} 2$ & $\mathrm{~S} 3$ & $\mathrm{~S} 4$ & $\mathrm{~S} 1$ & $\mathrm{~S} 2$ & $\mathrm{~S} 3$ & $\mathrm{~S} 4$ \\
\hline \multirow{2}{*}{ Patients } & 596 & 146 & 59 & 39 & 537 & 56 & 4 & 3 \\
& $(71 \%)$ & $(17 \%)$ & $(7 \%)$ & $(5 \%)$ & $(89 \%)$ & $(9 \%)$ & $(1 \%)$ & $(1 \%)$ \\
Controls & 584 & 9 & 4 & 3 & 594 & 1 & 3 & 2 \\
& $(97 \%)$ & $(2 \%)$ & $(1 \%)$ & $(1 \%)$ & $(99 \%)$ & $(.2 \%)$ & $(.5 \%)$ & $(.3 \%)$ \\
\hline
\end{tabular}

\section{Discussion}

Analysis of performance during the demonstration for photos and videos of motor tasks showed that the patients took longer to respond than the controls, suggesting that they had more difficulty in both demonstrations. This result may be related to a specific impairment of the mirror neuron system due to stroke (Buccino et al., 2004). Functional Magnetic Resonance Imaging (fMRI) has shown that action observation activates the premotor cortex in a somatotopic way (Avikainen, Forss, \& Hari, 2002). Given the location of the stroke-impaired areas in our patients, it is possible that the lesions might have contributed to their poor performance in this study, which was based on movement sequences of activities using the upper limb.
Importantly, the analysis revealed a significant difference between the time of recognition of videos and photos on the first trial and not the other trials, both for patients and for control subjects, possibly because the performance has stabilized quickly causing an effect "ceiling". However, it was necessary to keep the data in the first trial to total analysis to verify the best recognition pattern of motor sequences in tests with videos and photos in both groups (patients and controls). Thus, the results indicated that the patients took longer than control subjects to recognize the photos sequences than the videos sequences. The patients may have had difficulty in grouping the individual motor activity sequences presented statically in the photos, and in using them to form a coherent motor imagery. An alternative explanation 
is that the video-based presentation could have facilitated motor-sequence recognition by the patients. For instance, the sensory-motor system uses visual and proprioceptive signals differently when assessing a static or dynamic component of an activity (Chaminade, Ozto, Cheng, \& Kawato, 2008). Visual information predominates when the static context of a motor action is being identified and proprioceptive signals prevail with the dynamic components (Vogt \& Thomaschke, 2007). According to a study by Stinear and coworkers (Stinear, Byblow, Steyvers, Levin, \& Swinnen, 2006), a dynamic movement sequence is more effective for motor learning than a sequence of static visual images. These findings suggest that the videos may have allowed a better understanding of the action intention, thereby facilitating the performance of the patients in the present study.

A comparison of the 4 response types showed that the patients chose more frequently the sequences in which the movement was being correctly executed instead of the sequences in which only the goal of the activity had been reached, irrespective of the correctness of the movement sequence. This result is in accordance with the proposal that the human mirror neuron system codes the intention associated with the observation of an everyday action being performed by others (Iacoboni \& Mazziotta, 2007). The literature shows that when we watch human movements we are also covertly using our own movement representations, also we can use our own action system to understand the meaning of the behaviour of others. Action observation in this sense enables us to interact with other people and thus has a clear social function. This shared action system can use for learning new actions (de Vries \& Mulder, 2007).

According to Carr and Shepherd (2006), if patients are given several explanations or demonstrations of the activity to be performed, before beginning this activity, this is sufficient to provoke their memory of the movement and they may perform the entire activity without having to execute the components separately. The authors suggest that the environment needs to be organized so that the tasks are functionally relevant to the patient, with concrete goals such as: "reach and grab the glass on the table", instead of "raise your arm" (Carr \& Shepherd, 2006). In the present study, the presentation of continuous sequences using videos may have led to greater familiarity with daily activities; this also may explain the better performance of patients on the videos. Research suggests that videotherapy may have the advantage of to be easily administered at patient's home who will perform it on her/his own In times of restricted resources in the health system, it is of paramount importance to develop cost-efficient rehabilitation programs (Ertelt et al., 2012).

During all the trials in the present study, the participants were informed of the results with respect to the movement presented in the sequences, such as the objective of the action. Many studies show that reduced frequency in knowledge of result has a greater beneficial effect on learning, since this stimulates the activation of intrinsic feedback and error detection (Badets, Blandin, Wright, \&
Shea, 2006; Page, Wilson, Shiel, Carter, \& Norris, 2006; van Vliet \& Wulf, 2006). Therefore, this is a finding that demonstrates the importance of feedback in the motor relearning process.

The results found in this study can not be extended to all patients with stroke, but they are representative for the studied sample. In conclusion, our results show that stroke patients are better able to recognize when motor movements sequences are presented for videos, so dynamically, and not for photos, so static. These results may influence therapeutic strategies during motor rehabilitation.

\section{References}

Avikainen, S., Forss, N., \& Hari, R. (2002). Modulated activation of the human SI and SII cortices during observation of hand actions. Neuroimage, 15, 640-646. doi:10.1006/ nimg.2001.1029

Badets, A., Blandin, Y., Wright, D. L., \& Shea, C. H. (2006). Error detection processes during observational learning. Research Quarterly for Exercise and Sport, 77, 177-184. doi:1 0.1080/02701367.2006.10599352

Buccino, G., Binkofski, F., \& Riggio, L. (2004). The mirror neuron system and action recognition. Brain and Language, 89, 370-376. doi:10.1016/S0093-934X(03)00356-0

Caneda, M. A., Fernandes, J. G., Almeida, A. G., \& Mugnol, F. E. (2006). Confiabilidade de escalas de comprometimento neurológico em pacientes com acidente vascular cerebral. Arquivos de Neuro-Psiquiatria, 64, 690-697. doi:10.1590/ S0004-282X2006000400034

Carr, J. H., \& Sherpherd, B. R. (2006). The changing face of neurological rehabilitation. Revista Brasileira Fisioterapia, 10, 147-156. doi:10.1590/S1413-35552006000200003

Celnik, P., Webster, B., Glasser, D. M., \& Cohen, L. G. (2008). Effects of action observation on physical training after stroke. Stroke, 39, 1814-1820. doi:10.1161/ STROKEAHA.107.508184

Chaminade, T., Oztop, E., Cheng, G., \& Kawato, M. (2008). From self-observation to imitation: Visuomotor association on a robotic hand. Brain Research Bulletin, 75, 775-784. doi:10.1016/j.brainresbull.2008.01.016

De Vries, S., \& Mulder, T. J. (2007). Motor imagery and stroke rehabilitation: A critical discussion. Journal of Rehabilitation Medicine, 39, 5-13. doi:10.2340/16501977-0020

Ertelt, D., Hemmelmann, C., Dettmers, C., Ziegler, A., \& Binkofski, F. C. (2012). Observation and execution of upper-limb movements as a tool for rehabilitation of motor deficits in paretic stroke patients: Protocol of a randomized clinical trial. BMC Neurology, 12, 42. doi:10.1186/1471-2377-12-42

Ertelt, D., Small, S., Solodkin, A., Dettmers, C., McNamara, A., Binkofski, F., \& Buccino, G. (2007). Action observation has a positive impact on rehabilitation of motor deficits after stroke. Neuroimage, 36, T164-T173. doi:10.1016/j.neuroimage.2007.03.043

Gallese, V., Fadiga, L., Fogassi, L., \& Rizzolatti, G. (1996). Action recognition in the premotor cortex. Brain, 119, 593609. doi:10.1093/brain/119.2.593

Iacoboni, M., \& Mazziotta, J. C. (2007). Mirror neuron system: Basic findings and clinical applications. Annals of Neurology, 62, 213-218. doi:10.1002/ana.21198

Knott, M., \& Kabat, H. (1954). Proprioceptive facilitation therapy for paralysis. Physiotherapy, 40, 171-176. 
Krakauer, J. W. (2006). Motor learning: Its relevance to stroke recovery and neurorehabilitation. Current Opinion in Neurology, 19, 84-90.

Mukamel, R., Ekstrom, A. D., Kaplan, J., Iacoboni, M., \& Fried, I. (2010). Single-neuron responses in humans during execution and observation of actions. Current Biology, 20, 750-756. doi:10.1016/j.cub.2010.02.045

Page, S. J., Szaflarski, J. P., Eliassen, J. C., Pan, H., \& Cramer, S. C. (2009). Cortical plasticity following motor skill learning during mental practice in stroke. Neurorehabilitation and Neural Repair, 23, 382-388. doi:10.1177/1545968308326427

Page, M., Wilson, B. A., Shiel, A., Carter, G., \& Norris, D. (2006). What is the locus of the errorless-learning advantage? Neuropsychologia , 44, 90-100. doi:10.1016/j.neuropsychologia.2005.04.004

Parmelee, P. A., Thuras, P. D., Katz, I. R., \& Lawton, M. P. (1995). Validation of the Cumulative Illness Rating Scale in a geriatric residential population. Journal of the American Geriatrics Society, 43, 130-137.

Sale, P., \& Franceschini, M. (2012). Action observation and mirror neuron network: A tool for motor stroke rehabilitation. European Journal of Physical and Rehabilitation Medicine, 48, 313-318.

Schmidt, R. A. (1991). Motor learning and performance: From principles to practice. Champaign, IL: Human Kinetics.

Stefan, K., Cohen, L. G., \& Duque, J. (2005). Formation of a motor memory by action observation. The Journal of Neuroscience, 25, 9339-9346. doi:10.1523/JNEUROSCI.2282-05.2005

Stinear, C. M., Byblow, W. D., Steyvers, M., Levin, O., \& Swinnen, S. P. (2006). Kinesthetic, but not visual, motor imagery modulates corticomotor excitability. Experimental Brain Research, 168, 157-164. doi:10.1007/s00221-005-0078-y

Van Vliet, P. M., \& Wulf, G. (2006). Extrinsic feedback for motor learning after stroke: What is the evidence? Disability and Rehabilitation, 28, 831-840. doi:10.1080/09638280500534937

Vogt, S., \& Thomaschke, R. (2007). From visuo-motor interactions to imitation learning: Behavioural and brain imaging studies. Journal of Sports Sciences, 25, 497-517. doi:10.1080/02640410600946779

Williams, A., \& Gribble, P. L. (2012). Observed effectorindependent motor learning by observing. Journal of $\mathrm{Neu}$ rophysiology, 107, 1564-1570. doi:10.1152/jn.00748.2011 